\title{
Real-time model of synchronous reluctance motor drive for laboratory based investigations
}

Anuchin, A., Khanova, Y., Shpak, D. and Vagapov, Y.

This is a paper presented at the 42nd Conference of IEEE Industrial Electronics Society IECON-2016, Florence, Italy, 24-27 October 2016.

Copyright of the author(s). Reproduced here with their permission and the permission of the conference organisers.

\section{Recommended citation:}

Anuchin, A., Khanova, Y., Shpak, D. and Vagapov, Y. (2016), 'Real-time model of synchronous reluctance motor drive for laboratory based investigations'. In: Proc. 42nd Conference of IEEE Industrial Electronics Society IECON-2016, Florence, Italy, 24-27 October 2016, pp. 4989-4994, DOI: 10.1109/IECON.2016.7793879 


\section{Real-time Model of Synchronous Reluctance Motor Drive for Laboratory based Investigations}

\author{
Alecksey Anuchin, Yulia Khanova, Dmitriy Shpak \\ Department of Electric Drives \\ Moscow Power Engineering Institute \\ Moscow, Russia \\ anuchin.alecksey@gmail.com
}

\author{
Yuriy Vagapov \\ School of Applied Science, Computing and Engineering \\ Glyndwr University \\ Wrexham, United Kingdom \\ y.vagapov@glyndwr.ac.uk
}

\begin{abstract}
The Synchronous Reluctance Motor has received much attention in recent years as a very promising solution for electric drives in the near future. This paper presents a real-time model of the motor to be implemented into a software environment used for DSP control system development including debugging. The model is used in laboratory based investigations in academia in order to analyse the performance of electric drives based on a synchronous reluctance motor.
\end{abstract}

Keywords—synchronous reluctance motor; real-time model; DSP; engineering education

\section{INTRODUCTION}

A fundamental component of engineering education is a practical activity conducted in instructional laboratories. In the context of teaching and learning strategies the objective of practical activity is to improve the students' knowledge learned from classroom lectures and tutorials [1,2]. At the post graduate level this objective can be achieved through laboratory based investigations where students have to demonstrate "understanding of and ability to apply a systems approach to engineering problems" [3]. The actual content of laboratory based investigations depends on the subject area and has to underpin the students understanding of state-of-theart technologies.

The content of practical investigations in the area of Electric Drives and Motion Control has been dramatically changed in the past decade to reflect the progress in motor and control technologies. Modern electric drives utilise a variety of new types of electrical machines, advanced power converters and digital control systems operating under sophisticated control algorithms. Therefore practical investigations should be focused on the content related to microcontroller based control providing efficient and safe motor operation. Under this approach, the core of the practical experiment is conducted mainly at software level.

However, in order to apply a practical test to a real motor the experiment has to be conducted through two stages. At the first stage a student has to design a required control structure to drive a motor and then implement it into a virtual environment where the motor model is presented as a black box. A student should upload the control structure code into the project for Code Composer Studio IDE whereas the motor model is already incorporated in the project as a compiled file having ".obj" extension. At this stage the student can manipulate the motor drive by setting duty cycles of the inverter model and applying virtual load to the motor shaft. The student is also able to obtain data for feedbacks such as motor currents, speed and position.

The important benefit of the virtual implementation of the motor drive into the target microcontroller is that the student designs a control system by writing a code directly for the microcontroller as if it is a real drive. In order to ensure a reliable code execution the student should test it using realtime or step-by-step debugging. The first part of the experiment is completely safe as the motor hardware is not involved at this stage.

At the second stage, the motor model is replaced by a real hardware to convert the investigated drive control structure into a hardware-in-the-loop system. However, the converted system may not be powered before successful debug completion to ensure safe and reliable operation of the hardware. This approach to an experiment execution provides an increase in rated power of the motors and power converters involved into the practical investigation.

The two-stage method of the practical experiment can be applied to investigate the performance of any type of electric motor as part of drive system. However, apart from the motor hardware presence, the appropriate model of the motor has to be created and incorporated into the software environment in advance. Therefore the motor model is crucial for successful experiment execution. This paper discuses the model of the synchronous reluctance motor (SyncRM) designed to be implemented into two-stage laboratory based investigations where the students can analyse performance of both the model and the real motor. SyncRM has received much attention in the recent years as a very promising solution for industrial applications $[4,5]$.

\section{Synchronous ReluCtance Machine}

SynRM is one of the oldest types of electrical machines introduced by J.K. Kostko almost a century ago [4]. A long period of time the motor was not applicable for industrial installations due to starting problems and low power factor [6]. However, a few years ago ABB Company has 
brought to the market a range of SynRMs powered by the advanced power converters [4]. The offered motors have the same stator design as an induction machine but different concept of the rotor made of passive laminated steel without magnets or/and windings. SynRMs have the same number of pole pairs in stator and rotor (usually 2 or 3 ). Fig. 1 shows a cut-away view of a synchronous reluctance machine having 2 pole pairs. SynRMs are relatively expensive due to low production volume, however it is predicted that the mass production will significantly reduce the motor cost making it cheaper than induction motors. SynRMs have some major advantages comparing to another types of motors. These are:

- Simple and reliable design of the motor. Stator of induction machine and passive rotor are made of laminated steel.

- No losses in the rotor. No slip, no losses.

- Sensorless control in the full range of operation speeds including zero speed region. The motor has large magnetic anisotropy, thus it is suitable for the self-sensored control strategies.

Conversely the motor has some disadvantages:

- SynRM cannot operate directly from the grid. Unlike induction machines SynRM needs a power converter.

- Low power factor due to higher reactive current in comparison with other AC machines.

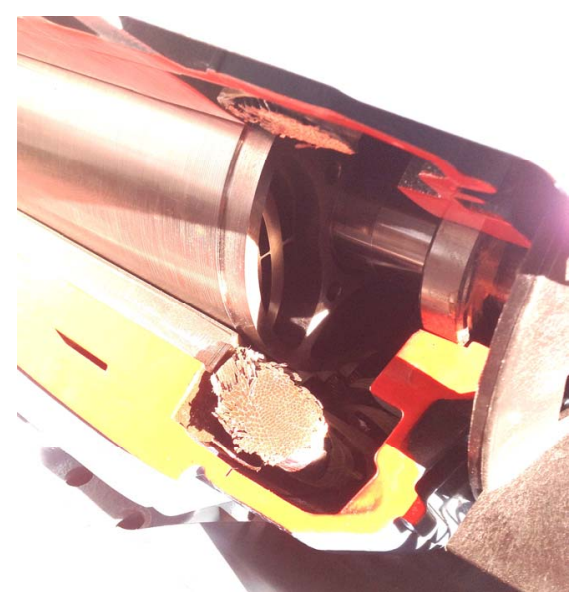

Fig. 1. A cut-away view of the ABB SynRM. The motor was exhibited at EPE-2014 conference in Lappeenranta, Finland.

\section{SynChronous Reluctance MAChIne DrIVE Model}

\section{A. The SynRM Model}

SynRM is a non-linear object. The magnetic circuit of the machine can be saturated under current even smaller than rated [3]. Therefore, some assumptions and simplifications should be taken into account in order to provide a fast model execution. The motor is modelled as a two-phase generalised electric machine. The stator equations written in stationary reference frame $\alpha, \beta$ are [8]:

$$
\left.\begin{array}{l}
v_{s \alpha}=i_{s \alpha} R_{s}+\frac{\mathrm{d} \psi_{s \alpha}}{\mathrm{d} t} \\
v_{s \beta}=i_{s \beta} R_{s}+\frac{\mathrm{d} \psi_{s \beta}}{\mathrm{d} t},
\end{array}\right\}
$$

where $v_{s \alpha}$ and $v_{s \beta}$ are the stator voltages, $i_{s \alpha}$ and $i_{s \beta}$ are the stator currents, and $\psi_{s \alpha}$ and $\psi_{s \beta}$ and are the flux linkages. The torque developed by the motor is:

$$
T=\psi_{s \alpha} i_{s \beta}-\psi_{s \beta} i_{s \alpha} .
$$

The magnetisation curves for different rotor angular positions define the relationship between stator currents and flux linkage as following:

$$
\left.\begin{array}{l}
\psi_{s \alpha}=L_{s \alpha, s \alpha}\left(\theta, i_{s \alpha}, i_{s \beta}\right) i_{s \alpha}+L_{s \alpha, s \beta}\left(\theta, i_{s \alpha}, i_{s \beta}\right) i_{s \beta} ; \\
\psi_{s \beta}=L_{s \beta, s \alpha}\left(\theta, i_{s \alpha}, i_{s \beta}\right) i_{s \alpha}+L_{s \beta, s \beta}\left(\theta, i_{s \alpha}, i_{s \beta}\right) i_{s \beta} .
\end{array}\right\}
$$

These relations are non-linear and extremely complex to be implemented in a real-time model. Therefore it is assumed that the current per one revolution is varying according to a sinusoidal law if the flux linkage is constant. Under this assumption the flux linkage equations can be written in the rotor reference frame $d, q$ :

$$
\left.\begin{array}{c}
\psi_{s d}=L_{s d}\left(i_{s d}\right) i_{s d} \\
\psi_{s q}=L_{s q}\left(i_{s q}\right) i_{s q}
\end{array}\right\}
$$

where $L_{s d}\left(i_{s d}\right)$ and $L_{s q}\left(i_{s q}\right)$ are relations between current and inductance.

However, the machine model can be built without equation (4). A much simpler approach is to implement the data of magnetisation curves in the model using a lookup table or an interpolation to determine directly the stator current corresponding to a known flux linkage. Fig. 2 shows a sample of the magnetisation curves for a SynRM [7]. The model calculates stator equation obtaining flux linkages and its derivative. The magnetisation curve is given for $d, q$ reference frames, therefore the next step is to transform flux linkages into the rotor reference frame:

$$
\left.\begin{array}{l}
\psi_{s d}=\psi_{s \alpha} \cos \theta+\psi_{s \beta} \sin \theta \\
\psi_{s q}=-\psi_{s \alpha} \sin \theta+\psi_{s \beta} \cos \theta
\end{array}\right\}
$$

After the flux linkages transformation into the rotor reference frame the stator currents can be obtained from the magnetisation curves. This is the reason why the magnetisation curves are presented as current vs. flux linkage rather than vice versa.

The magnetisation curves can be interpolated using a second order equation where the difference between first three points provides the initial derivatives for current:

$$
i^{\prime}[0]=\frac{2 i[1]-1.5 i[0]-0.5 i[2]}{\Delta \psi},
$$




$$
i^{\prime \prime}[0]=\frac{i[2]+i[0]-2 i[1]}{\Delta \psi^{2}}
$$

where $i[0], i[1]$ and $i[2]$ are the current values corresponding to the first points of the magnetisation curve, and $\Delta \psi$ is the fixed step for flux linkage. The first derivative for the next step can be evaluated by:

$$
i^{\prime}[k]=i^{\prime}[k-1]+i^{\prime \prime}[k-1] \Delta \psi,
$$

and the second derivative by:

$$
i^{\prime \prime}[k]=2 \frac{i[k+1]-i[k]-i^{\prime}[k] \Delta \psi}{\Delta \psi^{2}} .
$$

For a particular flux linkage $\psi$ located in segment $k$ between $\psi[k]$ and $\psi[k+1]$, the current can be evaluated by the following equation:

$$
i=i[k]+i^{\prime}[k](\psi[k]-\psi)+i^{\prime \prime}[k] \frac{(\psi[k]-\psi)^{2}}{2} .
$$

All first and second derivatives can be evaluated during initialisation of the model, thus the recalculation of the current from the flux linkage comprises of 3 additions and 3 multiplications. The second order interpolation provides smoother varying of the current value in a saturation knee area comparing to a linear interpolation (see Fig. 2).

At the next stage the currents obtained in $d, q$-axes are transformed to the stationary reference frame:

$$
\left.\begin{array}{l}
i_{s \alpha}=i_{s d} \cos \theta-i_{s q} \sin \theta ; \\
i_{s \beta}=i_{s d} \sin \theta+i_{s q} \cos \theta .
\end{array}\right\}
$$

The result obtained from (11) is used in (1) and (2) for the flux linkage and torque evaluation. In terms of computational method the motor model utilises a second-order Runge-Kutta algorithm in a single precision floating point.

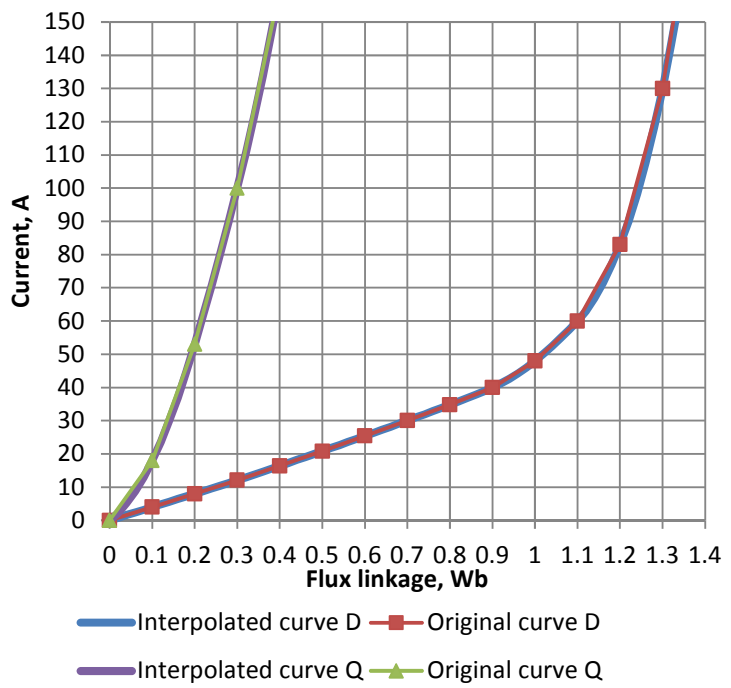

Fig. 2. Magnetisation curves of the SynRM

\section{B. The Power Converter and Sensors Model}

The schematic diagram of the whole model is shown in Fig. 3. It consists of a 3-phase power converter having current sensors in two phases, SynRM, and the control system based on TMS320F28xx microcontroller. All data from sensors and references for the inverter are contained in one structure called "drive". A student have an access to the PWM generator via timer period register "tpr", dead time duration register " $d t$ ", and compare level registers "cmprx" setting the references for the inverter legs. All these registers are represented in ticks of the PWM timer operating normally at a frequency of $150 \mathrm{MHz}$ for TMS320F281x and TMS320F28335 microcontrollers.

The inverter is represented as a zero-order hold. Electrical potential for each phase is calculated at each PWM cycle using the following equation:

$$
\varphi_{x}=V_{D C} \frac{C M P R x-0.5 \times \operatorname{sign}\left(i_{x}\right) \times D T}{T P R},
$$

where $V_{D C}$ is the dc-link voltage, $i_{x}$ is the current in the phase $x$.

Currents and speed are measured by the current sensors and tachogenerator and then converted by $\mathrm{ADC}$ into a code available for the microcontroller. The ADC noise is added to the actual value using the equation below:

$$
A D C_{x}=0 \mathrm{xFFF} 0 \&\left(k_{\text {sensor }} \cdot x+0 \mathrm{x} 7 \mathrm{FE} 0+16 \cdot \operatorname{rnd}(3)\right),
$$

where $x$ is the exact value of the measured signal from the model, 0x7FE0 is offset, $k_{\text {sensor }}$ is scale factor of ADC and sensor. The currents and speed can be accessed via variables " $i A$ ", " $i B$ ", and "adcSpeed" respectively.

The rotor position can be sensed using incremental encoder or Hall-sensor. The data of incremental encoder position are stored in "qepCounter" variable. The data can vary from zero to a number of pulses per revolution. Hallsensor state can be monitored via "hallSensor" variable.

The model includes current and speed protection tool indicating the fault conditions in "fault" variable. During the debugging process student can refer to "time" variable of the model time.

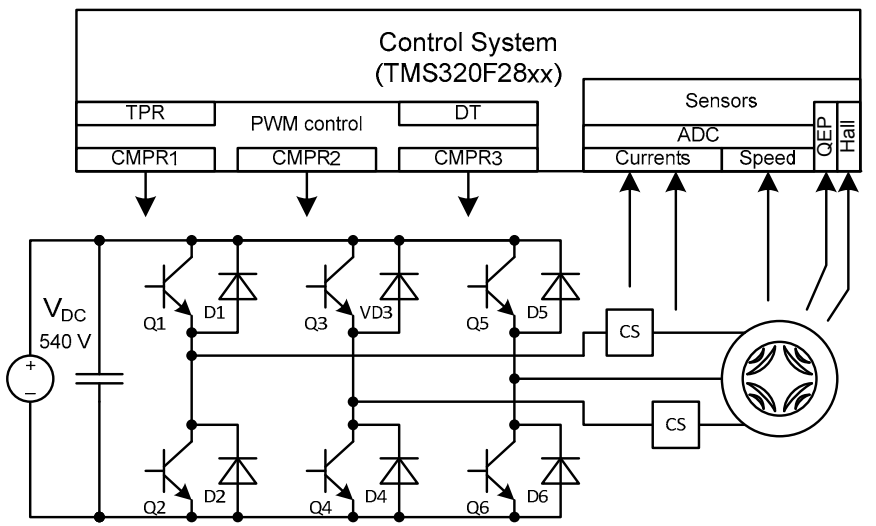

Fig. 3. Schematic diagram of the SynRM drive model including power converter, motor, sensors and the control system 
The work with the model is performed in several steps, starting from motor parameters estimation, writing the control system code, debugging of the developed control system, and ending with the performance tests of the considered control strategy. It may be flux-vector control [9] or direct torque control [10], sensorless or with position encoder, with some additional function like field weakening [10], position loop and so on.

\section{MODEL TESTS}

\section{A. Voltage Step Response Test}

In order to validate the model several tests were performed. First is an experiment of voltage step response. The inverter reference registers were loaded with the constants of 8000 for phase A and 7600 for phases B and C. This corresponds to the phase voltage of $9.6 \mathrm{~V}$ and it is aligned with the $d$-axis position. The response in current is shown in Fig. 4. The current curve changes the derivative according to the magnetization curve of $d$-axis. At the beginning of the process the derivative is small due to high inductance. When current reaches the level of $50 \mathrm{~A}$ the derivative starts growing because the saturation knee is reached. Finally the voltage drop across resistance $\left(R_{S}=0.06 \Omega\right)$ becomes significant and the phase current reaches its steady value of $159 \mathrm{~A}$.

\section{B. Close-loop Field-oriented Control Test}

Field-oriented control system for this type of motor is very similar to control strategies for PMSM. The difference between them is in the flux loop. The $d$-axis current for PMSM is usually set to zero or is negative, because the flux is produced by permanent magnets. In case of SynRM this current defines the excitation of the motor. The developed torque is defined by the following equation:

$$
T=\left(L_{d}-L_{q}\right) i_{s d} i_{s q}
$$

thus, the maximum torque (per ampere) is produced if the $d$ and $q$-axis currents are equal in their absolute values [11]. This is true only for a linear motor having constant inductances. With respect to this particular case it is needed only to check the rated power of the motor under load at the rated current. Therefore, the control system is designed assuming that (14) is true. However, other control strategies and distribution of $d$ and $q$-axis currents can be used to obtain better efficiency, response speed etc. $[9,11]$. These problems form a topic to be investigated by students using the model.

The structure of the control system shown in Fig. 5 has PI current controllers and no speed loop. The speed here is to be controlled by applying a load to the motor shaft.

The example of the control system code is presented in Fig. 6. This code is written and debugged in Code Composer Studio IDE in $\mathrm{C}$ language using floating point arithmetic. All operations are implemented directly in the PWM cycle interrupt except the routines of PI controllers. This code is written according to the block diagram from Fig. 5 and that is an example how students fulfil their tasks.

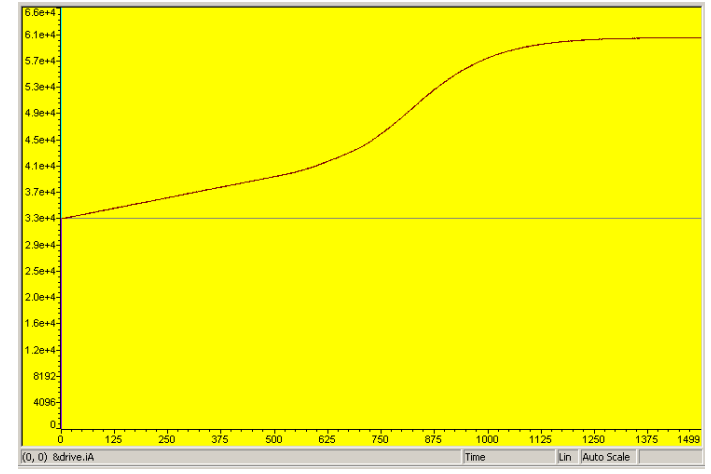

Fig. 4. Current curve in the phase A under the voltage step response test; time is in PWM cycles; the current is in ADC scale.

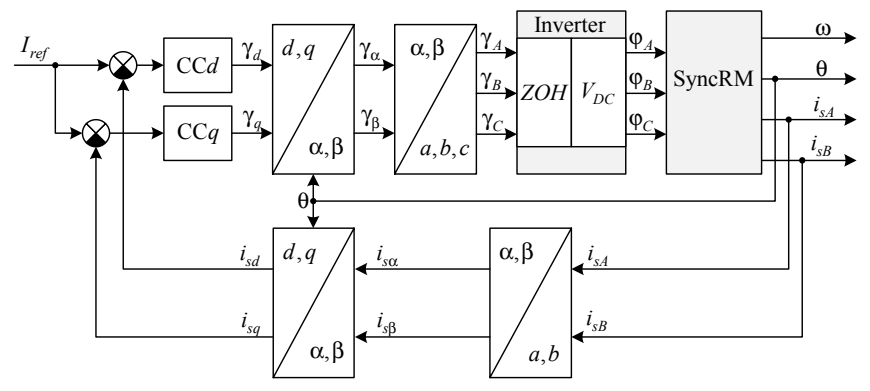

Fig. 5. Block diagram of a field-oriented control system for SynRM (CCd is $d$-axis current controller; $\mathrm{CC} q$ is $q$-axis current controller; $\mathrm{ZOH}$ is zero order hold).

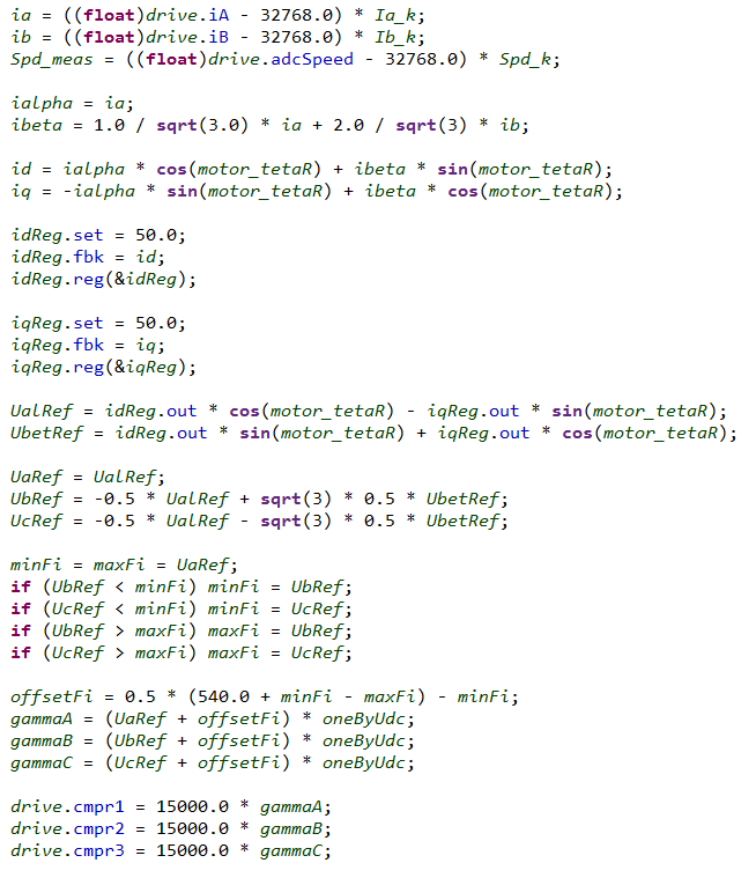

Fig. 6. Example of the control system code for Code Composer Studio IDE

Code starts with the conversion of the ADC data to SI units. Then the phase currents are transformed to stator reference frame $\alpha, \beta$. Next, they are rotated to the rotor reference frame $d, q$ to provide feedback for the PI current controllers. The PI current controllers produces the references 
in the rotor reference frame, which should be transformed back to the stator reference frame and to the references for A, $\mathrm{B}$, and $\mathrm{C}$ phases. Finally, space-vector PWM is implemented.

The transients of $d$ - and $q$-axes currents in Fig. 7 show that the performance of these control loops is different due to various inductances in $d$ - and $q$-axes. It can be seen that each axes current reached the reference value of $50 \mathrm{~A}$. The tunings of the current controllers are also different in terms of proportional gain dependent on inductance. It has been found that the frequency of currents in the phase A and B are increased under the motor acceleration up to the speed value of $161 \mathrm{rad} / \mathrm{s}$. At this condition the current magnitude is $70.7 \mathrm{~A}$ and the developed torque is $128 \mathrm{Nm}$.

\section{Power Balance Test}

The next exercise is a power balance test. The test is conducted for a steady state condition at a particular moment of time using corresponding instant values of voltages, currents, torque and speed. The required data of the instant values are presented in Fig. 8. The instant mechanical power $P_{\text {mech }}$ is found using the following equation:

$$
P_{\text {mech }}=T_{\text {mech }} \frac{\omega_{\text {electr }}}{p_{p}}=128.2 \times \frac{161.1}{2}=10327 \mathrm{~W},
$$

where $T_{\text {mech }}$ is mechanical torque; $\omega_{\text {electr }}$ is electrical speed; $p_{p}$ is number of pole pairs. The instant power from the power converter $P_{\text {supply }}$ is calculated as following:

$$
\begin{gathered}
P_{\text {supply }}=v_{A} i_{A}+v_{B} i_{B}+v_{C}\left(-i_{A}-i_{B}\right)= \\
=-17 \times 51+153 \times 17-136 \times(-51-17)=11003 \mathrm{~W},
\end{gathered}
$$

where $v_{A}, v_{B}$, and $v_{C}$ are the instant voltages in the phase $\mathrm{A}$, $\mathrm{B}$, and $\mathrm{C} ; i_{A}$ and $i_{B}$ are the instant currents in the phase A and $\mathrm{B}$. The ohmic losses $\Delta P_{\text {ohmic }}$ are:

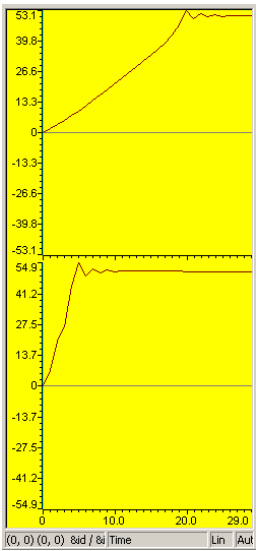

a)

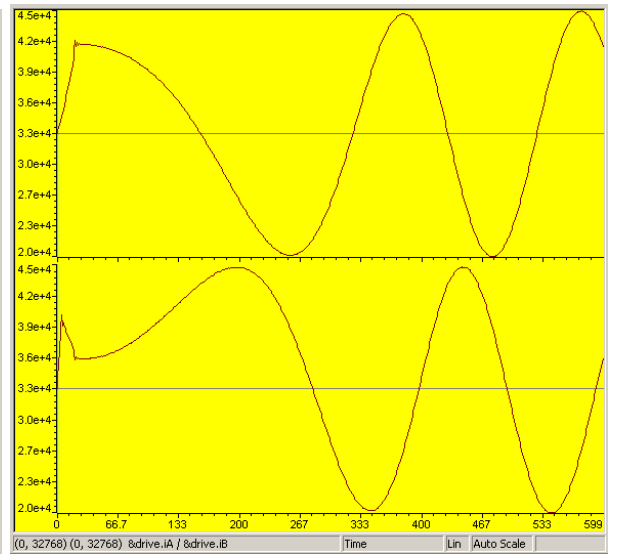

b)
Fig. 7. Transients in the motor operating under the field-oriented control: a) upper plot is d-axis current in amps, lower plot is q-axis current in amps; b)

\begin{tabular}{|c|c|}
\hline Name & Value \\
\hline motor.torque & 128.2348 \\
\hline$\diamond$ motor omega & 161.0642 \\
\hline$\diamond$ motor.ua & -17.04001 \\
\hline$\Leftrightarrow$ motor.ub & 152.916 \\
\hline$\otimes$ motor.uc & -135.876 \\
\hline$\diamond$ motorisa & 50.92347 \\
\hline$\theta$ motorisPhaseB & 17.14705 \\
\hline$\vartheta$-motor.isa-motor.isPhaseB & 68.07053 \\
\hline$\checkmark$ motor.torque ${ }^{x}$ motor.omega/motor.pp & 10327.02 \\
\hline 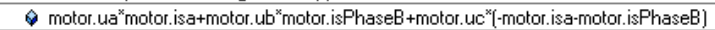 & 11003.47 \\
\hline Q motor. is a ${ }^{x}$ motor. isa ${ }^{x}$ motor. rs + motor. isPhaseB ${ }^{x}$ motor. isPhaseB ${ }^{x}$ motor. Is+(-motor. isa-... & 451.2491 \\
\hline
\end{tabular}
upper plot is the current in phase $\mathrm{A}$ in $\mathrm{ADC}$ scale, lower plot is the current in phase $\mathrm{B}$ in ADC scale. Time is in PWM cycles
Fig. 8. Power balance data for a steady operation mode

$$
\begin{gathered}
\Delta P_{\text {ohmic }}=i_{A}^{2} R_{s}+i_{B}^{2} R_{s}+\left(-i_{A}-i_{B}\right)^{2} R_{s}= \\
=51^{2} \times 0.06+17^{2} \times 0.06+(-51-17)^{2} \times 0.06=451 \mathrm{~W} .
\end{gathered}
$$

A small difference between the supplied power and the sum of mechanical power on the shaft and ohmic losses is explained by some minor dynamics issues in the drive and control system.

\section{CONCLUSIONS}

The two-stage approach has been introduced at Electric Drives Department of Moscow Power Engineering Institute to provide laboratory investigations within the subject of Control Systems of Electric Drives [12]. This subject includes the theory of electromechanical energy conversion, power electronics, and microcontroller systems, and delivers principles of design of modern control systems of electric drives of various types. Four types of motors can be currently available for examining in the departmental instructional laboratory. These include a permanent magnet synchronous machine $(180 \mathrm{~W})$, induction machine drive $(1.5 \mathrm{~kW}), \mathrm{DC}$ motor drive $(1.9 \mathrm{~kW})$ and switched reluctance drive $(2.2 \mathrm{~kW})$ $[13,14]$. The real-time models of these motors was developed and implemented into Texas Instruments motor control DSPs based on TMS320F2812, TMS320F28335, TMS320F28035 and a novel Russian microcontroller NT32M4F1 (CortexM4F) from NIIET [12, 15]. The models were successfully used for students' courseworks and projects for a few years.

The proposed model of SynRM drive has been recently developed to extend the laboratory works portfolio. This type of motor is predicted to be a very promising solution for electric drives in the near future due to its reliability, simplicity, and controllability.

\section{ACKNOWLEDGMENT}

The paper is supported by the Russian Science Foundation grant (Project № 16-19-10618).

\section{REFERENCES}

[1] N.S. Edward, "The role of laboratory work in engineering education: Student and staff perceptions," Int. Journal of Electrical Engineering Education, vol. 39, no. 1, pp. 11-19.

[2] G. Heitmann, "Challenges of engineering education and curriculum development in the context of the Bologna process," European Journal of Engineering Education, vol. 30, no. 4, Dec. 2005, pp. 447-458.

[3] Engineering Council, UK Standard for Professional Engineering Competence. London: Engineering Council UK, 2013. 
[4] G. Brown, "Developing synchronous reluctance motors for variable speed operation," in Proc. 6th IET Int. Conf. on Power Electronics, Machines and Drives, Bristol, UK, 2012, 6p.

[5] R.R. Moghaddam, F. Magnussen, and C. Sadarangani, "Theoretical and experimental reevaluation of synchronous reluctance machine," IEEE Trans. on Industrial Electronics, vol. 57, no. 1, pp. 6-13, Jan. 2010.

[6] V. Dmitrievskii, V. Prakht, V. Kazakbaev, A. Pozdeev, and S. Oshurbekov, "Development of a high efficient electric drive with synchronous reluctance motor," in Proc. 18th Int. Conf. on Electrical Machines and Systems, Pattaya, Thailand, 2015, pp. 876-881.

[7] W. Peng, J. Gyselinck, A. Dziechciarz, C. Martis, "Magnetic Equivalent Circuit Modelling of Reluctance Machines", 2016 Eleventh International Conference on Ecological Vehicles and Renewable Energies (EVER)

[8] S.-K. Sul, "Control of Electric Machine Drive Systems", February 2011, Wiley-IEEE Press, p. 424.

[9] Y. Inoue, S. Morimoto, M. Sanada, "A novel control scheme for maximum power operation of synchronous reluctance motors including maximum torque per flux control", International Conference on Electrical Machines and Systems, 2009, p. 6.

[10] G. Foo, X.N. Zhang, "Robust Direct Torque Control of Synchronous Reluctance Motor Drives in the Field Weakening Region", IEEE Transactions on Power Electronics, 2016, in press.
[11] R. E. Betz, R. Lagerquist, M. Jovanovic, T. J. E. Miller, R. H. Middleton, "Control of synchronous reluctance machines", IEEE Transactions on Industry Applications, 1993, Volume: 29, Issue: 6, pp. 1110-1122.

[12] A. Anuchin, D. Savkin, Y. Khanova, D. Grishchuk, "Real-time model for motor control coursework", 2015 IEEE 5th International Conference on Power Engineering, Energy and Electrical Drives (POWERENG), 2015, pp. $427-430$.

[13] A. Anuchin, C. Belloc, Y. Vagapov, "Development of curriculum for a postgraduate course on Electric Drives and Motion Control", 50th Universities Power Engineering Conference (UPEC 2015), Staffordshire University, 1-4 September 2015.

[14] A. Anuchin, Y. Vagapov, "Configurable Control Systems of Power Converters for Instructional Laboratories", 6th International conference on Internet Technologies \& Application, Wrexham, Glyndwr University, 8-11 September 2015.

[15] A. Anuchin, D. Grishchuk, A. Zharkov, Y. Prudnikova, L. Gosteva, "Real-time Model of Switched Reluctance Drive for Educational Purposes", RTUCON 2016, submitted. 